\title{
For Small Renal Tumors, Kidney Sparing Surgery Provides Local Tumor Control and Prevents Chronic Kidney Disease
}

\author{
Paul Russo \\ Department of Surgery, Urology Service, Memorial Sloan Kettering Cancer Center, New York, NY, USA
}

\begin{abstract}
Adamakis and colleagues from Athens, Greece, report a series of 43 patients with renal cell carcinoma who underwent partial nephrectomy during a 7 year period from 1998-2005 [1]. In this data set, clinical parameters were similar to what we are seeing currently in the United States and include a median age of 58.7 years, a median tumor size of $3.3 \mathrm{~cm}, 89 \%$ of which were P1a $(<4 \mathrm{~cm})$, and, after a median follow up of 32 months, there were 5 deaths from renal cancer and two local tumor recurrences. The overall cancer-specific survival was $95.4 \%$ and the overall progression-free survival was $93 \%$. These outcomes also closely parallel the experience at our center, and other American centers such as the Mayo Clinic and Cleveland Clinic, which speaks to the oncological soundness of kidney sparing surgery. Missing from their report were the number of patients operated upon during this same time period that had a benign tumor resected, the number of patients that had radical nephrectomy during this time period, and the impact of the kidney sparing approach upon post operative kidney function.
\end{abstract}

The clinical landscape concerning the management of small renal tumors continues to change and now urologists must incorporate new and important information as they plan operations. Today, $70 \%$ of renal masses are detected incidentally when abdominal imaging is done for other reasons such as the evaluation of non-specific abdominal or musculoskeletal complaints or during the follow up or diagnosis of other malignancies. The median tumor size is approximately $4 \mathrm{~cm}$, well within safe limits for partial nephrectomy if technically feasible. It is now known that approximately $20 \%$ of these masses deemed suspicious enough for surgical resection are benign tumors including oncocytoma and fat-poor angiomyolipoma, 25\% are indolent tumors with limited metastatic potential, such as papillary and chromophobe carcinoma, and 54\% represent the more potentially malignant conventional clear cell carcinoma that uncommonly achieves its metastatic potential when $4 \mathrm{~cm}$ or less. Accumulating clinical evidence indicates that partial nephrectomy, first for tumors of $4 \mathrm{~cm}$ or less, and recently for conventional clear cell tumors of up to $7 \mathrm{~cm}$ [2], provides equally effective local tumor control as does radical nephrectomy with survival rates of $90 \%$ or greater depending on the histological sub-type. Patients remain at lifetime risk for ipsilateral tumor recurrence (likely new tumor formation) and asynchronous contralateral tumor recurrence of approximately $5 \%$ and hence lifelong imaging of the kidney is recommended.

Now that long-term survival is a strong probability for nearly all patients undergoing resection of a small renal tumor, important concerns for their overall long-term renal health have come into focus. Although radical nephrectomy will not precipitate immediate dialysis in the vast majority of patients, the initiation or worsening of chronic kidney disease has now emerged as an important concern. This condition, defined as a glomerular filtration rate (GFR) of less than $60 \mathrm{ml} / \mathrm{min} /$ $1.73 \mathrm{~m}^{2}$, is now considered an independent risk factor for the development of cardiovascular disease, hospitalization, and death, the likelihood of which increases as the GFR decreases [3]. Using the modification of diet in renal diseases (MDRD) equation to estimate GFR in a retrospective cohort study of 662 apparently well patients with a normal serum creatinine and 2 kidneys, investigators from our group studied the impact of radical nephrectomy $(\mathrm{n}=204)$ and partial nephrectomy $(\mathrm{n}=458)$ on GFR. To our surprise, prior to operation, 171 patients $(26 \%)$ had chronic kidney disease with a GFR $<60 \mathrm{ml} / \mathrm{min} / 1.73 \mathrm{~m}^{2}$. Following surgery, the 3-year probability of freedom from new onset of GFR $<60 \mathrm{ml} / \mathrm{min} / 1.73 \mathrm{~m}^{2}$ was $80 \%$ in the $\mathrm{PN}$ group, compared to $35 \%$ in the $\mathrm{RN}$ group; and for new onset of GFR <45, a level of severe chronic kidney disease, was $95 \%$ in the PN group, compared to $64 \%$ in the $\mathrm{RN}$ group (both $\mathrm{p}<0.0001$ ). On multivariate analysis, $\mathrm{RN}$ remained an independent and significant risk factor for develop-

\begin{tabular}{|c|c|}
\hline KARGER & (c) 2007 S. Karger GmbH, Freiburg \\
\hline $\begin{array}{l}\text { Fax +49 } 7614520714 \\
\text { E-mail Information@Karger.de } \\
\text { www.karger.com }\end{array}$ & $\begin{array}{l}\text { Accessible online at: } \\
\text { www.karger.com/onk }\end{array}$ \\
\hline
\end{tabular}


ing new onset of GFR $<60$ (hazard ratio (HR) 3.82; 95\%-CI: 2.75, 5.32; $\mathrm{p}<0.0001)$ and GFR $<45 \mathrm{ml} / \mathrm{min} / 1.73 \mathrm{~m}^{2}$ (HR 11.8; 95\%-CI: 6.24, 22.4; p < 0.0001) [4].

Despite the strong case for partial nephrectomy as the major treatment for small renal tumors, evidence from the SEER and National Inpatient Sample databases indicates that across the United States more than $90 \%$ of patients with small renal tumors still undergo radical nephrectomy [5]. Similar data from England and Canada have been generated. The overzealous use of radical nephrectomy for small renal tumors, by either open or laparoscopic techniques, must now be considered surgical overkill as well as detrimental to the longterm health and safety of the patient with a small renal cortical tumor. Widespread training in partial nephrectomy, either by open or laparoscopic approaches, is clearly indicated. The urologist facing a new patient with a small renal mass must pause to consider long-term renal functional preservation, the initiation or worsening of preexisting chronic kidney disease and its subsequent cardiovascular risk enhancement on an equal par to local tumor control and surgical convalescence when counseling their patient. A pre-surgical calculation of GFR estimate, patient age, tumor size, and the presence of significant medical co-morbidity, particularly in an elderly patient, can also make the strong case for active surveillance in selected patients. Radical nephrectomy must be reserved for patients with massive renal tumors not amenable to kidney sparing operations.

\section{References}

Adamakis I, Koutallelis G, Mitropoulos G, Vourekas S, Constantinides C, Zervas A: Enucleoresection for the elective treatment of small renal cell carcinoma: can it be the treatment of choice? Onkologie 2007;30:97-102.

2 Dash A, Vickers AJ, Schachter LR, Bach AM, Snyder ME, Russo P: Comparison of outcomes in elective partial vs. radical nephrectomy for clear cell renal cell carcinoma of 4-7 cm. BJU Int 2006;97:939-945.

3 Go, AS, Chertow GM, Fan D, McCulloch CE, Hsu CY: Chronic kidney disease and the risks of death, cardiovascular events, and hospitalization. N Eng J Med 2004;351:1296-1305.

4 Huang WC, Levey AS, Serio AM, Snyder M, Vickers A, Scardino PT, Russo P: Chronic kidney disease after nephrectomy in patients with renal cortical tumors: a retrospective cohort study. Lancet Oncol 2006;7:735-740.

5 Miller DC, Hollingsworth JM, Hafez KS, Daignault S, Hollenbeck BK: Partial nephrectomy for small renal masses. An emerging quality of care concern? J Urol 2006;175:853-857. 